\title{
Cost and Benefit of Tax Reduction: Evidence from China's Pension Fee Collection
}

\author{
Fei Han \\ School and Public Finance and Taxation, Central University of Finance and Economics, Beijing, China \\ Email address: \\ aotian87@live.cn \\ To cite this article: \\ Fei Han. Cost and Benefit of Tax Reduction: Evidence from China's Pension Fee Collection. Journal of Finance and Accounting. \\ Vol. 9, No. 1, 2021, pp. 1-7. doi: 10.11648/j.jfa.20210901.11
}

Received: December 22, 2020; Accepted: January 5, 2021; Published: January 12, 2021

\begin{abstract}
Tax reduction policies often implies a trade-off of government between revenue loss and economic boost, which although relates to social governance and economic development. However, the existing literature rather focuses on the economic impacts than the direct pecuniary costs and benefits. To fill the gap in the literature, comparing the direct pecuniary cost and benefit is important for policymaking. Thus, this study aims to evidence the causal impact of potential tax reduction on local revenue loss and economic gain via a case study of China's pension fee. To address the simultaneity between its collection and the corresponding labour output, this study takes the retiree in the prior period as the instrumental variable. Drawing on a provincial panel data, the two-stage-least-square regressions show that by lowering 1 percentage point pension fee rate (PFR), local pension revenue will decrease by 6.3 percent or 2.1 billion yuan, which indeed generates certain revenue distress; meanwhile, it instead increases employment and wages and leads to growth in the local GDP by 0.84 percent or 113.6 billion yuan, which far exceeds the revenue loss and generates net economic gain. Heterogeneity further shows that this economic benefit is more significant in the less developed areas. Accordingly, it is suggested that tax-cut policy can be a beneficial device to balance the inter-regional differences in economic development.
\end{abstract}

Keywords: Pension Fee Rate Reduction, Revenue Loss, GDP Boost

\section{Introduction}

Policies aiming to lower tax rates are frequently considered by policymakers, especially when an economic downturn impends. However, making such policies bears the pressure of losing fiscal revenue that is important to maintain the well-being of local social governance. This is more crucial in developing countries where the local fiscal capacity is constrained and the local society is still in transition with various social tensions. Subsequently, it is important to advance the understanding in the causal impact of tax cut on the revenue and the economic output, especially in developing countries that have been under-investigated for long.

Drawing on the case of pension fee collection in China, this study directly focuses on comparing the pecuniary cost - the revenue loss - and the benefit - production gain - of potential tax reduction policy. China's pension reflects as a pay-as-you-go (pooling) system and collects its revenue from firms with contributions from both the employer and the employee. China's PFR, with a mandatory contribution rate of
$24 \%-28 \%$ on firms, is ranked as one of the highest in the world, causing significant burden on doing business [1]. Thus, China deems PFR-cut as the pivotal part of its fiscal reform that aims to lower the burden of the economy. Moreover, this case is important because: 1 ) it shows how a large developing country weighs economic growth against the sustainability of its massive social pension program; 2) it demonstrates how effective and beneficial a tax-cut policy can be in an environment where the labour force is sufficient.

This study uses a provincial-level panel data covering the period from 2008 to 2016. However, the identification in OLS model should fail due to simultaneity between current production, pension fee revenue and the PFR. Consequently, this study applies an instrumental variable approach. Given than the number of retirees only affects the revenue target and thus plays a role in determining the effective PFR but does not intervene the current production, it is feasible to be the proxy variable of the unobserved enforcement intensity and the instrumental variable of the effective PFR. This instrumental variable activates the causal chain from enforcement to the 
PFR and then to the revenue and the economic output.

The empirical evidence shows that lowering the PFR by 1 percentage point would shrink the pension revenue by $6.38 \%$ or 2.1 billion yuan, an unneglectable pressure on local pension payment. However, it can also lead to an extra GDP growth by 0.84 percentage point or 113.6 billion yuan far exceeding the revenue loss in terms of the magnitude of actual value, which creates net earnings and an implicit transfer from government to the market. Considering that more GDP could boost local fiscal capacity in return, the overall benefit of lower the PFR should be bigger. Moreover, further heterogeneity examination demonstrates that this net-earning effect is more significant in the less developed areas that used to have higher PFRs and less populations.

This study makes several contributions. First, it adds to the voluminous literature on the effect of tax reduction by providing evidence of developing countries [2-5]). Unlike previous empirical studies that only focused on changes in economic development or labour market, this study lends additional insight by combining and comparing them. Second, it contributes to the literature on tax and development [6-7]. By showing tax reduction could be more beneficial in less developed areas, this study highlights that tax reduction policies can be useful in helping the backward. Third, this study echoes the research in payroll tax reduction. Like Kugler and Kugler [8], lowering the PFR or payroll tax rate can substantially increase employment and wages. The rest parts of this study proceed as follow: the second part reviews the literature; the third part discusses the data, variables, and the empirical strategy; the fourth part carries out instrumental variable regression analyses, the mechanism investigation, and the heterogeneity examination; the last part concludes with policy implications.

\section{Literature}

A voluminous literature focuses on social security or pension-related tax policies, most of which try to examine the tax incidence and the elasticity of labour supply or demand in different environment. Saez et al. [9] investigate the payroll tax reform in Greek that grants more bargaining power to the union. They found that the after-reform employees stop paying their contributions without lowering their wages. This discovery challenges the classic public finance theory that the statutory policy does not affect the tax incidence. Chetty et al. [10] use Danish administrative-level data and event-study strategy and find that even if the employer pays more payroll tax for the employee, the lowered wage would still increase the saving ratio of the employee. Saez et al. [11] document that the Swedish payroll tax reimburse policy that aimed to increase the employment of the young (no more than age 26) would in fact achieve so without harming the income of employees of other age groups (larger than 26) and the profit of the firm.

Another strand of literature focuses on how policy affect the capacity of social security program. Gruber and Wise [12] examine 12 nations' data and discover that the policy that encourage early retirement to create more jobs for the young can indeed decrease employment of both the senior and the junior. This shrinkage of employment in turn deviates the original intention of the policy - increase the dependency ratio. Wise [13] and Coile and Borsch-Supan [14] both find that policies that encourage late retirement can substantially increase the capacity of social security programs.

Studies on developing countries instead rather focus on the informality. Adrian et al. [15] document that 2012's payroll tax reduction in Columbia significantly increases the number of formal labours and lengthens the contract of low-wage employees. Moreover, this can help small firms more than the big ones. Ulyssea [16] uses Brazilian administrative-data and finds that a $10 \%$ payroll tax reduction could increase formal employees by $22.5 \%$ via simulation, which also improves the overall economic efficiency.

Meanwhile, the research on China rather highlights the compliance. Yuan et al. [17], Nielson and Smyth [18], and Zhao et al. [19] all find that the higher social security fee rates of China are, the less the compliance of the firm is. Zhao and $\mathrm{Lu}$ [20] further evidence that higher social security fee rates can suppress the innovation and the economic efficiency.

However, these literatures yet provide various evidence regarding the socio-economic effect of social security tax or pension fee rate of China, they do not stress the direct fiscal trade-off that government is facing - revenue or GDP. In other word, these empirical findings are more indirect for policymaking, especially when the fiscal capacity is limited.

\section{Data, Variables, and Empirical Strategy}

\subsection{Data}

Aiming to shed fresh light on the abovementioned gap in the literature, this study compares the effects of the PFR change on pension fee revenue and the local GDP.

This study uses China's aggregated data at provincial level to implement the research inquiry for two reasons. First, the data could better match the operation of a provincial-level discretionary system because it can correctly measure the regional effective pension fee rate that actually go into the information set of local government. Second, data regarding pension and retirees at lower levels is hardly available. The data is selected from China's Statistical Yearbook and China City Statistical Yearbook which are collected and organized by National Bureau of Statistics of China, and I exclude Tibet, Hongkong, Macau and Taiwan areas due to their exceptive fiscal institutions. The sample covers 30 provinces and the 8 years between 2008 and 2016, which forms a balanced panel data.

The selection of this sample period is based on four concerns: 1 . the provincial-based pension system was not established by the end of 2008; 2. between 2008 and 2016, it is fortunate that no province had changed the pension collecting administration, which helps avoid noises in the data caused by window-dressing behaviors and provides a rather clean observing window ; 3 . it excludes the noises caused by the difference between pre- and post-financial crisis, especially 
the impact of the counter-cyclical " 4 trillion plan" on local government's fiscal and monetary policies; 4 . it reserves most observations as possible, because data on the average wage in the urban private sector is only available since 2008 .

\subsection{Variables}

The core dependent variables are pension fee revenue and the local GDP. The core explanatory variable of this study is the effective PFR. To reflect the overall change of local market, this study adopts an average-rate approach. That is, the PFR is measured by the following equation:

$$
\text { Pension Fee Rate }=\text { Pension Fee Revenue } / \text { Local Total Wage }
$$

Control Variables refer to five aspects. First, this study exploits the local GDP per capita to capture local developmental level. Second, this study adds urban population to control for the scale effect of local population. Third, I control the local fiscal revenue to hold other factors that can affect enforcement and revenue demands constant. Fourth, the overall fiscal spending on social security is controlled to absorb the impact of relevant fiscal expenditure. Last, the number of private firms is added as the covariates because: 1) firm number is a sensitive indicator of the local economy; 2) private firms are more sensitive to labour costs than the state-owned large-scale enterprises in China; 3) alternative variables, such as total urban firm number, is available in less years. The statistic descriptions of the above variables are listed in the below table 1.

Table 1. Statistic Descriptive.

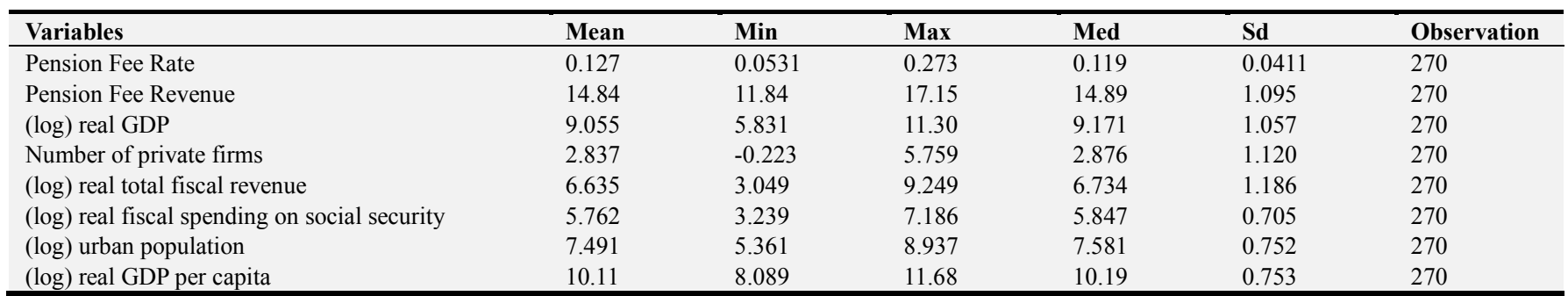

\subsection{Empirical Strategy}

In China's pension system, local government tends to adjust regional effective PFR for dual policy objectives maintaining the well-being of the senior or easing the labour cost of local firms. However, the presence of this mechanism makes the identification fail due to simultaneity. On the one hand, government can adjust the enforcement and thus change the PFR and the labour costs, which potentially distorts the current production decisions. On the other hand, local economic output may in turn affect the fiscal capacity, or the employment can change the dependency ratio and thus affect the demand for pension fee revenue.

With a perspective of Wright-Cowles identification [21], this study argues that the retiree should not affect current-period production but play a role in determining the PFR. Consequently, the number of retirees can be used as the instrumental variable to locally depict the "curve" of the PFR which is independent of production decision [22]. Here, the number of retirees is a proxy variable of the unobserved enforcement and a feasible instrument variable for the PFR.

Notice that although the retiree no longer participates in the production of current period, the vacancies left by them should become a part of employment decision in the beginning of current period production, which weakens its feasibility. Thus, this study extends to prior terms to overcome this problem.

\section{Regression and Results}

\subsection{OLS Regressions}

To start with, this study implements OLS regressions for reference. In the following Model (1), $Q_{i t}$ is the pension fee revenue; $t_{i t}$ denotes the PFR; $X_{i t}$ represents the covariates; $s_{i}$ and $T$ are regional and year fixed effects; $\mu_{i t}$ is the residual. To highlight the robustness and insensitivity, in tables 2 and 3, this study exploits multiple estimators, including OLS, two-way-fixed-effects without control variables, two-way-random-effects without control variables, two-way-fixed-effects with control variables, and two-way-random-effects with control variables.

$$
Q_{i t}=\alpha+\beta t_{i t}+\Gamma X_{i t}+T+s_{i}+\mu_{i t}
$$

As displayed in the table 2 , the PFR is positively and significantly correlated with the Revenue (except in the column 1). Comparing the column 2 and 3, 4 and 5, it is observed that the estimated coefficient is insensitive to fixed or random-effect model setting. With the presence of control variables, the estimated coefficient increases by $30 \%$ to $40 \%$ in column 4 and 5, suggesting the entirety of control variables are negatively correlated with the revenue.

Next, this study examines the correlation between the PFR and the local GDP in the table 3 . With the 5 estimators used in table 2 , the results are sensitive to control variables and the model setting in table 3 . When the control variables are absent, the PFR significantly and negatively correlates with the GDP, which is counter-intuitive because it implies that higher labour cost can be boost the economy. Meanwhile, the column 4 and 5 in table 3 show that the PFR is not significantly correlated with the local GDP after adding the control variables. 
Table 2. OLS Regressions on Pension Fee Revenue.

\begin{tabular}{|c|c|c|c|c|c|}
\hline \multirow{3}{*}{ Variables } & (1) & (2) & (3) & (4) & (5) \\
\hline & OLS & TWFE & TWRE & TWFE & TFRE \\
\hline & Revenue & Revenue & Revenue & Revenue & Revenue \\
\hline Pension Fee Rate & -1.2837 & $3.0246^{* * *}$ & $3.0103 * * *$ & $4.3661^{* * *}$ & $3.9255 * * *$ \\
\hline Number of Private Firms & (1.2315) & $(0.7404)$ & $(0.7290)$ & $\begin{array}{l}(0.5706) \\
0.1602 * \\
(0.0948)\end{array}$ & $\begin{array}{l}(0.5960) \\
0.0685 \\
(0.0909)\end{array}$ \\
\hline Total Fiscal Revenue & & & & $\begin{array}{l}0.2898 * * * \\
(0.1071)\end{array}$ & $\begin{array}{l}0.2452 * * * \\
(0.0974)\end{array}$ \\
\hline Fiscal Spending on Social Security & & & & $\begin{array}{l}0.1563 * \\
(0.0891)\end{array}$ & $\begin{array}{l}0.1140 * \\
(0.0705)\end{array}$ \\
\hline Urban Population & & & & $\begin{array}{l}0.3644 * * * \\
(0.1113)\end{array}$ & $\begin{array}{l}-0.2587 \\
(0.3000)\end{array}$ \\
\hline GDP per capita & & & & $\begin{array}{l}0.1864 * * \\
(0.0834)\end{array}$ & $\begin{array}{l}0.1774 * \\
(0.1088)\end{array}$ \\
\hline Province Fixed Effect & NO & YES & YES & YES & YES \\
\hline Year Effect & $\mathrm{NO}$ & YES & YES & YES & YES \\
\hline Constant & $\begin{array}{l}15.5525^{* * *} \\
(0.1651)\end{array}$ & $\begin{array}{l}14.3079 * * * \\
(0.1089)\end{array}$ & $\begin{array}{l}14.3099 * * * \\
(0.1899)\end{array}$ & $\begin{array}{l}6.4056 * * * \\
(1.0827)\end{array}$ & $\begin{array}{l}11.9331 * * * \\
(2.1900)\end{array}$ \\
\hline Observations & 270 & 270 & 270 & 270 & 270 \\
\hline
\end{tabular}

Notes: standard errors in parentheses; $* * *, *$, and $*$ denote statistical significance at the $1 \%, 5 \%$, and $10 \%$ levels, respectively.

Table 3. OLS Regressions on the Local GDP.

\begin{tabular}{|c|c|c|c|c|c|}
\hline \multirow{3}{*}{ Variables } & (1) & (2) & (3) & (4) & (5) \\
\hline & OLS & TWFE & TWRE & TWFE & TFRE \\
\hline & GDP & GDP & GDP & GDP & GDP \\
\hline Pension Fee Rate & $\begin{array}{l}-1.1995^{* * *} \\
(0.4245)\end{array}$ & $\begin{array}{l}-1.1890 * * * \\
(0.4278)\end{array}$ & $\begin{array}{l}-1.1995 * * * \\
(0.4245)\end{array}$ & $\begin{array}{l}0.1136 \\
(0.1161)\end{array}$ & $\begin{array}{l}-0.0568 \\
(0.1924)\end{array}$ \\
\hline Number of Private Firms & & & & $\begin{array}{l}-0.0230 \\
(0.0214)\end{array}$ & $\begin{array}{l}-0.0325 \\
(0.0281)\end{array}$ \\
\hline Total Fiscal Revenue & & & & $\begin{array}{l}0.1186^{* * * *} \\
(0.0402)\end{array}$ & $\begin{array}{l}0.1242 * * * \\
(0.0405)\end{array}$ \\
\hline Fiscal Spending on Social Security & & & & $\begin{array}{l}0.0004 \\
(0.0138)\end{array}$ & $\begin{array}{l}0.0062 \\
(0.0226)\end{array}$ \\
\hline Urban Population & & & & $\begin{array}{l}0.2650^{* *} \\
(0.1038)\end{array}$ & $\begin{array}{l}0.8206^{* * * *} \\
(0.0610)\end{array}$ \\
\hline GDP per capita & & & & $\begin{array}{l}0.6994 * * * \\
(0.0841)\end{array}$ & $\begin{array}{l}0.5619 * * * \\
(0.0788)\end{array}$ \\
\hline Province Fixed Effect & $\mathrm{NO}$ & YES & YES & YES & YES \\
\hline Year Effect & $\mathrm{NO}$ & YES & YES & YES & YES \\
\hline Constant & $\begin{array}{l}9.1668 * * * \\
(0.1861)\end{array}$ & $\begin{array}{l}9.1653 * * * \\
(0.0619)\end{array}$ & $\begin{array}{l}9.1668 * * * \\
(0.1861)\end{array}$ & $\begin{array}{l}-0.7312 \\
(0.6507)\end{array}$ & $\begin{array}{l}-3.4800^{* * *} \\
(0.8115)\end{array}$ \\
\hline Observations & 270 & 270 & 270 & 270 & 270 \\
\hline
\end{tabular}

Notes: standard errors in parentheses; $* * *, * *$ and $*$ denote statistical significance at the $1 \%, 5 \%$, and $10 \%$ levels, respectively.

Comparing tables 2 and 3, lowering PFR can bring more revenue loss than output gains. Especially when the control variables are in the regressions, every 1 percentage point of the PFR reduction can lead to a 4 percent pension revenue shrinkage but does not generate more GDP. Under this circumstance, the cost overwhelms the benefit.

\subsection{Instrumental Variable Regressions}

However, the aforementioned simultaneity can result the identification in failure. In other words, tables 2 and 3 do not display any causal impacts of certain policies. Thus, it is necessary to apply the instrument variable approach discussed above to unravel the causality of interest. In the following two-stage-least-square model of 2 and 3 , the $R_{i, t-1}$ denotes the number of retirees in the previous term, while $v_{i t}$ is the residual of the second stage.

$$
\begin{gathered}
t_{i t}=\alpha+\beta R_{i, t-1}+\Gamma X_{i t}+T+s_{i}+\mu_{i t} \\
Q_{i t}=\alpha^{\prime}+\gamma t_{i t}+\Gamma X_{i t}+T+s_{i}+v_{i t}
\end{gathered}
$$

The column 1 of table 4 demonstrates that the instrumental variable significantly has positive effect $(0.084)$ on the PFR and thus is relevant for the causal inference. The F statistics of Wald tests far exceed the rule-of-thumb threshold of 10 and thus shows that the instrumental variable is not weak. The column 2 displays that the pension fee revenue significantly increases by 6.37 percentage on each 1 percentage point of the PFR increase. This estimated coefficient of the IV estimator is larger in the magnitude than the ones in table 2 . The column3 reports the reduced-form regression, where the 0.5351 equals $\beta \cdot \gamma$, significant at the $1 \%$ level, suggesting that the instrumental variable is not correlated 
with residuals and the embedded causality should exist.

Table 4. 2SLS Regressions on Pension Fee Revenue.

\begin{tabular}{llll}
\hline \multirow{2}{*}{ Variables } & $\mathbf{( 1 )}$ & $\mathbf{( 2 )}$ & (3) \\
\cline { 2 - 4 } & First Stage & Second Stage & Reduced-form \\
\cline { 2 - 4 } & Pension Fee Rate & Revenue & Revenue \\
\hline Pension Fee Rate & & $6.3768^{* * *}$ & $(0.4206)$ \\
(lag) Number of Retirees & $0.0839^{* * *}$ & & $0.5351^{* * *}$ \\
& $(0.0066)$ & & $(0.0436)$ \\
Number of Private Firms & $-0.0454^{* * *}$ & $0.4864^{* * *}$ & $0.1967^{* * *}$ \\
& $(0.0074)$ & $(0.0522)$ & $(0.0518)$ \\
Total Fiscal Revenue & 0.0002 & $0.1832^{* * *}$ & $0.1844^{* *}$ \\
& $(0.0116)$ & $(0.0616)$ & $(0.0779)$ \\
Fiscal Spending on Social Security & -0.0029 & $0.2308^{* * *}$ & $0.2123^{* * *}$ \\
Urban Population & $(0.0072)$ & $(0.0506)$ & $(0.0604)$ \\
& $-0.0399^{* *}$ & $0.1570^{* * *}$ & -0.0974 \\
GDP per capita & $(0.0083)$ & $(0.0542)$ & $(0.0692)$ \\
& $-0.0188^{* * *}$ & $0.2733^{* * *}$ & $0.1538^{* *}$ \\
Province Fixed Effect & $(0.0085)$ & $(0.0486)$ & $(0.0599)$ \\
Year Effect & YES & YES & YES \\
Constant & YES & YES & YES \\
Observations & $0.3705^{* * *}$ & $6.0792^{* * *}$ & $8.4420^{* * *}$ \\
Weak IV Wald test F statistics:158.38 & $(0.0955)$ & $(0.6494)$ & $(0.6456)$ \\
\hline
\end{tabular}

Notes: standard errors in parentheses; $* * *, * *$, and $*$ denote statistical significance at the $1 \%, 5 \%$, and $10 \%$ levels, respectively.

It is implied in the table 4 that lowering the PFR can cause revenue loss. During the sample period, hold other factors constant, if the PFR decrease by $1 \%$, the pension fee revenue will lose 2.13 billion yuan, or $3.14 \%$ of each province's pension fee revenue per year. Then, how much economic benefit can such a pecuniary cost generate?

To answer the question, this study uses the above instrumental variable estimator to examine the impact of the PFR on the local
GDP. As shown in the column 2 of table 5, contrary to the OLS regression in table 3 , every 1 percentage point of the PWR increase could significantly lower the local GDP by 0.84 percent. This implies that higher labour cost has suppressing impact on the local economy. During the sample period, lowering the PFR can generate more GDP by 113.6 billion yuan, far exceeding the pension fee loss. It is observed that lower the PFR in fact has net pecuniary gain for the overall local economy.

Table 5. 2SLS Regressions on the Local GDP.

\begin{tabular}{llll}
\hline \multirow{2}{*}{ Variables } & $\mathbf{( 1 )}$ & $\mathbf{( 2 )}$ & $\mathbf{( 3 )}$ \\
\cline { 2 - 4 } & Pension Fee Rate & GDP & GDP \\
\hline Pension Fee Rate & & $-0.8414^{* * *}$ & $(0.2001)$ \\
(Lag) Number of Retirees & $0.0875^{* * *}$ & & $-0.0736^{* * * *}$ \\
& $(0.0060)$ & & $(0.0174)$ \\
Number of Private Firms & $-0.0454^{* * *}$ & $-0.1306^{* * *}$ & $-0.0924^{* * *}$ \\
& $(0.0075)$ & $(0.0215)$ & $(0.0216)$ \\
Total Fiscal Revenue & -0.0029 & $0.0569^{*}$ & $0.0594^{*}$ \\
& $(0.0107)$ & $(0.0313)$ & $(0.0310)$ \\
Fiscal Spending on Social Security & -0.0077 & -0.0125 & -0.0060 \\
& $(0.0074)$ & $(0.0205)$ & $(0.0212)$ \\
Urban Population & $-0.0342^{* * *}$ & $1.0989^{* * *}$ & $1.1276^{* * *}$ \\
& $(0.0088)$ & $(0.0238)$ & $(0.0255)$ \\
GDP per capita & -0.0048 & $0.5299^{* * *}$ & $0.5339^{* * *}$ \\
& $(0.0078)$ & $(0.0221)$ & $(0.0224)$ \\
Province Fixed Effect & YES & YES & YES \\
Year Effect & YES & YES & YES \\
Constant & $0.1984^{* *}$ & $-4.3064^{* * *}$ & $-4.4733^{* * *}$ \\
Observations & $(0.0856)$ & $(0.2325)$ & $(0.2471)$ \\
Weak IV Wald test F statistics: 192.62 & 270 & 270 & 270 \\
\hline
\end{tabular}

Notes: standard errors in parentheses; $* * * * *$, and $*$ denote statistical significance at the $1 \%, 5 \%$, and $10 \%$ levels, respectively. 
Based on the above empirical findings, this study argues that it is feasible to lower the PFR for further economic development. Moreover, given that the more economic output is, the higher the fiscal revenues are, the positive effects of lowering the PFR can be larger than the direct GDP gain of 113.6 billion. Between 2008 and 2016, the elasticity of fiscal revenue on GDP is 0.46 in China, which means that almost half of each 1 percent GDP growth can be transferred into the fiscal revenue. This general equilibrium effect can further mitigate the fiscal pressure caused by the pension fee revenue loss.

\subsection{Further Calculation}

\subsubsection{Mechanism}

This subsection looks into the underlying mechanism that causes revenue loss and GDP growth. This study focuses on the changes of labour output and investment. In table 6, investment, employment, and wages are respectively examined. However, considering these three factors belong the same production decision procedure, their standard errors can be overestimated owing to the co-variation effect. Thus, this study takes three-stage-least-square regression as the estimator.

As can be seen in table 6, increase in the PFR can, at the $1 \%$ level, significantly lower the employment and wages (by 0.77 and 1.00 percent). Meanwhile, it can also significantly increase the investment by 1.5 percent at the $10 \%$ level. This implies that changes in the PFR have labour cost effects. The higher the cost is, the more the investment is due to substitution between labour and capital. Correspondingly, the substitutive elasticity between capital and labour is $0.85(1.5 /$ $(0.77+0.9950))$, slightly lower than one, showing that the Chinese economy is more sensitive to labour output.

According to Blanch flower and Oswald [23], lower the PFR can increase the profitability of the labour. Thus, the opportunistic costs of labour idling increase, which can lead to growth in both employment and wages. Comparing with the reduction in investment, lowering the PFR can generate more labour output than the investment $((0.77+1)>1.5)$, which can explain both the revenue loss and the GDP growth.

Table 6. Impacts on Investment, Wages, and Employment, 3SLS.

\begin{tabular}{|c|c|c|c|c|}
\hline \multirow{2}{*}{ Variables } & (1) & (2) & (3) & (4) \\
\hline & Pension Fee Rate & Fixed-asset Investment & Average Wages & Employment \\
\hline \multirow[t]{2}{*}{ Pension Fee Rate } & & $1.5053 *$ & $-0.7700 * * *$ & $-0.9950 * * *$ \\
\hline & & $(0.8828)$ & $(0.2512)$ & $(0.3736)$ \\
\hline \multirow[t]{2}{*}{ (Lag) Number of Retirees } & $0.0853 * * *$ & & & \\
\hline & $(0.0061)$ & & & \\
\hline Province Fixed Effect & YES & YES & YES & YES \\
\hline Year Effect & YES & YES & YES & YES \\
\hline \multirow[t]{2}{*}{ Constant } & $0.1957 * *$ & $-6.9399 * * *$ & $9.3315 * * *$ & 0.4467 \\
\hline & $(0.0890)$ & $(1.0321)$ & $(0.2937)$ & $(0.4368)$ \\
\hline Observations & 270 & 270 & 270 & 270 \\
\hline
\end{tabular}

Notes: standard errors in parentheses; $* * *, * *$, and $*$ denote statistical significance at the $1 \%, 5 \%$, and $10 \%$ levels, respectively.

\subsubsection{Heterogeneity}

Further, this study investigates the heterogeneity across regions. This study calculates the proportion of local-originated residents in the total resident population and defines those has more than 50\% non-local-origin residents are population inflow regions (I) and those with no more than $50 \%$ are population outflow regions $(\mathrm{O})$. The inflow regions are the 6 most developed and populous provinces (Guangdong, Zhejiang, Fujian, Shanghai, Beijing, and Tianjin).

Using the 2sls estimator in tables 4 and 5, this subsection compares the pension fee revenue and GDP between inflow regions and the outflow ones. Table 7 shows that the revenue loss caused the PFR decrease does not vary much between the inflow regions (5.23) and the outflow (6.22). Meanwhile, the incurred GDP boost substantially differs. In the inflow regions, lowering the PFR has no significant impact on the local GDP while in the outflow regions, reducing the PFR could create more GDP by 1.42 percentage.

This study argues that the heterogeneity between two kinds of regions is caused by the marginal diminishing effect. Since the outflow regions used to have higher PFRs, lowering the PFR has bigger marginal effects on the GDP; while the inflow regions are populous and their dependency ratio is higher, thus the PFR is lower and the marginal effect of reducing the PFR is insignificant. This finding has important policy implication that lowering the PFR can generate more economic gain in the less-developed and less-populated areas while only cause revenue loss in the developed regions. Consequently, the government should consider focusing on region-specific tax reduction policies to help the less developed areas, which is instrumental to developmental balance and fairness among regions. 
Table 7. Inter-regional Heterogeneity.

\begin{tabular}{lllll}
\hline \multirow{2}{*}{ Variables } & $(\mathbf{1})$ & $\mathbf{( 2 )}$ & $\mathbf{( 3 )}$ & (4) \\
\cline { 2 - 5 } & Revenue(I) & GDP(I) & Revenue(O) & GDP(O) \\
\hline Pension Fee Rate & $5.22889^{* * *}$ & -0.2571 & $6.2218^{* * *}$ & $(0.3642)$ \\
& $(1.4976)$ & $(0.3898)$ & YES & $(0.2323)$ \\
Control Variables & YES & YES & YES & YES \\
Province Fixed Effect & YES & YES & YES & YES \\
Year Effect & YES & YES & 216 & 216 \\
Observations & 54 & 54 & $234^{* * *}$ & \\
\hline
\end{tabular}

Notes: standard errors in parentheses; $* * *, * *$, and $*$ denote statistical significance at the $1 \%, 5 \%$, and $10 \%$ levels, respectively.

\section{Conclusion}

With comparing the impacts of the PFR changes on pension revenue and local GDP, this study investigates the potential pecuniary costs and benefits of PFR reduction policies. To address the simultaneity in identification, this study employs the number of retirees in prior periods as the instrumental. Two-state-least-square regressions show that lowering the PFR can generate more GDP to offset the pension fee revenue loss, which can be seen as a net-earning for the local economy. This study further unravels that this is the consequence of the fact that lowering the PFR can create a faster growth in labour output than the decrease in investment. This demonstrates that increasing the labour output is the dominant mechanism that boosts the GDP. Moreover, the empirical findings indicate that lowering the PFR creates bigger net-earnings in the less developed areas that used to have higher PFR, which can be the consequence of bigger marginal effect of PFR decrease.

The empirical findings bear dual implications for policymaking. On the one hand, tax reduction policies do generate revenue loss, but the GDP increase can well compensate certain fiscal distress. This is more meaningful in front of a globe-wise depression. On the other hand, tax reduction policies can be further exploited in the less developed and less-populated areas. This can be important for developing countries that have massive labour migration and more under-developed regions. Region-specific tax reduction can mitigate the inter-regional imbalances, which can promote both the socio-economic well-being and the fairness across regions.

\section{References}

[1] Adriana D. Kugler, M. Kugler and L. Herrera-Prada, 2017. "Do Payroll Tax Breaks Stimulate Formality? Evidence from Colombia's Reform" Economia Journal of the Latin American and Caribbean Economic Association, 1: 3-40.

[2] Angrist, J. and J. Pischke, 2009. Mostly Harmless Econometrics: An Empiricist's Companion. New Jersey: Princeton University Press.

[3] Besley, T., and T. Persson. 2013. "Taxation and Development." In Handbook of Public Economics, eds A. Auerbach, R. Chetty, M. Feldstein, E. Saez, 51-110, Amsterdam: North Holland.

[4] Besley, T., and T. Persson. 2014. "Why Do Developing Countries Tax So Little?" Journal of Economic Perspective 28 (4): 99-120.
[5] Blanch flower, D., and A. Oswald, 2003. Wage Curve, MA: MIT press.

[6] Chetty, R., J. Friedman, S. Leth-Peterson, T. Nielsen, and T. Olsen, 2014. "Active vs. Passive Decisions and Crowd-out in Retirement Savings Accounts: Evidence from Denmark" The Quarterly Journal of Economics, 129 (3): 1141-1219.

[7] Coile, C., A. Borsch-Supan, 2018. "Social Security Programs and Retirement Around the World: Reforms and Retirement Incentives" NBER working paper. 25280.

[8] Fang. H. M., and J. Feng. 2018. "The Chinese Pension System." NBER working paper, no. 25088.

[9] Gruber, J. and D. Wise, 2010. Social Security Programs and Retirement Around the World: The Relationship to Youth Employment. Chicago: University of Chicago Press.

[10] Lewbel, A. 2019. "Identification Zoo: Meanings of Identification in Econometrics", Journal of Economic Literature, 57 (4):8 35-903.

[11] Li Zhigang and Wu Minqi, 2011. "Estimating the incidences of the recent pension reform in China: evidence from 100,000 manufacturers". BBVA Research working paper, No.11/38.

[12] Nielsen, I. and R. Smyth, 2008. "Who bears the burden of employer compliance with social security contributions? Evidence from Chinese firm level data" China Economic Review, 19: 230-244.

[13] Saez, E. and M. Matsaganis and P. Tsakloglou, 2012. "Earnings Determination and Taxes: Evidence from a Cohort-Based Payroll Tax Reform in Greece" The Quarterly Journal of Economics, 127: 493-533.

[14] Saez, E. and B. Schoefer and D. Seim, 2017. "Payroll Taxes, Firm Behavior, and Rent Sharing: Evidence from a Young Workers' Tax Cut in Sweden" NBER Working paper, no. 27936.

[15] Wise, D., 2017. Social Security Programs and Retirement Around the World: The Capacity to Work at Older Ages. Chicago: University of Chicago Press.

[16] Ulyssea, Gabriel, 2018. "Firms, Informality and Development: Theory and evidence from Brazil" American Economic Review, 108: 2015-47.

[17] Yuan, Z. G., Z. Li, and J. Feng, 2009. "Urbanization and Pension Dependency Ratio in China" Nankai Economic Research, 2009 (4).

[18] Zhao, J. Y. and Z. F. Lu, 2018. "Pension Fee Rate and Economic Efficiency” Economic Research Journal, 2018 (10).

[19] Zhao, J, J. Mao, and L. Zhang, 2015. "Social Security Rate and Compliance - A Study on Employee and Firm Avoidance" Economics (Quarterly), 2015 (1). 